\title{
Comunitats de pràctiques per a la inclusió educativa. Una 'recerca basada en el disseny'
}

\author{
Carolayn Marín-Suanzo * \\ Silvia Camps-Orfila ** \\ David Garcia-Romero *** \\ Sònia Sanchez-Busqués ${ }^{* * * *}$ \\ José Luis Lalueza
}

\section{Resum}

El Projecte Shere Rom és una «recerca basada en el disseny» iniciada fa vint-i-u anys. En aquest article es descriu un dels espais d'aquest projecte desenvolupat durant catorze anys en una escola del barri barceloní del Bon Pastor, amb població amb alt risc d'exclusió social. Aquesta experiència està basada en el model «Cinquena Dimensió», orientat al desenvolupament de comunitats educatives interinstitucionals, intergeneracionals i interculturals que promouen pràctiques d'aprenentatge col.laboratiu recolzat en l'ús de les tecnologies de la informació i la comunicació. Es tracta d'espais en els que nois i noies de la comunitat resolen tasques o creen relats digitals en cooperació amb estudiants universitaris involucrats en un programa d'aprenentatge Servei (ApS). S'analitza l'experiència a partir de dos elements propis de l'enfocament històric-cultural de la Psicologia, la historicitat i la multivoceïdat (multiplicitat de veus), i dels reptes derivats del seu caràcter col/laboratiu, l'apropiabilitat per actors amb diferents motius, l'estructura narrativa i el foment de l'agència a través de l'autoria.

\section{Paraules clau}

Comunitats de pràctiques, aprenentatge col-laboratiu, recerca per disseny, educació intercultural, aprenentatge servei

\section{Recepció original: 2 de gener de 2020}

Acceptació:24 d'abril de 2020

Publicació: 16 de desembre de 2020

\section{Necessitats socials i objectius del projecte}

El Projecte Shere Rom, que s'orienta a la inclusió escolar de nois i noies de grups minoritaris i en risc d'exclusió social, intenta construir una via de resposta a la deficient situació de l'escolarització d'aquests col-lectius, en els que són freqüents l'absentisme, l'abandonament precoç i el fracàs escolar. La intervenció es centra en dos elements que estan en la base d'aquesta situació: I'absència de sentit en l'experiència escolar de molts d'aquests

$\left.{ }^{*}\right) \quad$ Professora d'història i geografia, Màster en desenvolupament curricular i projecte educatiu, Scholarship program Xile, CONICYT, Màster en Psicologia de l'educació (MIPE), actualment Doctorat en Psicologia de l'educació (DIPE) per la Universitat Autònoma de Barcelona. Adreça electrònica: carol.masu@gmal.com

${ }^{* *}$ Graduada en Psicologia, amb especialització en Psicologia Social i de l'Educació. Coordinadora del projecte Shere Rom (recerca acció) a l'àmbit d'intervenció socioeducativa. Adreça electrònica: silviacampsorfila@gmail.com.

$\left(^{* * *}\right)$ Investigador post doctoral a la Universitat Autònoma de Barcelona. Docència universitària en assignatures del grau de psicologia als àmbits de psicologia educativa i psicologia social. Adreça electrònica: david.garcia.romero@uab.cat

$\left(^{* * *}\right)$ Doctora en psicologia de l'educació. Membre de l'equip DEHISI i especialitzada en metodologia d'investigació qualitativa. Adreça electrònica: sonia.sanchez@uab.cat

(****) Professor titular del Departament de Psicologia Bàsica, Evolutiva i de l'Educació. Director de l'equip DEHISI i del projecte de recerca-acció Shere Rom. També forma part del grup promotor d'Aprenentatge-Servei en universitats catalanes i del Grup d'Innovació Docent-ApS a la Universitat Autònoma de Barcelona. Adreça electrònica: joseluis.lalueza@uab.cat 
alumnes, i les relacions de poder entre comunitats que porten als membres d'alguns col-lectius minoritaris (com ara els gitanos), a interpretar la seva identitat en oposició a la participació escolar (Fernández-Enguita, 1994; Ogbu, 1994).

En aquest projecte, enfront de formes d'aprenentatge per transmissió que descuiden els interessos de l'alumne, es proposa l'aprenentatge significatiu generat per la participació en els objectius de les tasques i la col-laboració en l'assoliment de metes. I enfront de les dinàmiques de dominació i resistència, es proposa l'aprenentatge basat en la constant negociació i cooperació. El nucli del projecte està dirigit al treball amb població infantil i adolescent, mitjançant un conjunt d'activitats d'aprenentatge amb un clar caire lúdic i que tinguin la potencialitat de crear un espai intercultural on l'accés al coneixement propi de l'escola no es presenti com un món aliè a la cultura familiar i comunitària. Es pretén substituir els models de transmissió escolar per un altre fonamentat en la col.laboració. La promoció del desenvolupament d'habilitats instrumentals i comunicatives es fa mitjançant la creació de nous referents i models vitals a través de la col·laboració entre nois i noies de la comunitat i estudiants universitaris .

En el seu origen, en 1998, l'activitat es fonamentava en el desenvolupament de competències digitals, de manera que alfabetització digital i pràctica col-laborativa anaven de la mà. Actualment, si bé es manté aquesta estratègia, les competències digitals ja no són un terreny inexplorat per l'escola, de manera que la participació dels nois i noies en el projecte ja no és la única via d'entrada al món digital. Així, en tant que està garantida una mínima competència bàsica d'ús de les TIC, situem ara en el centre de la nostra estratègia l'ús d'aquestes tecnologies en el desenvolupament de competències comunicatives, i orientem l'activitat a una audiència potencial i real en diàleg amb els agents, els nois i noies.

\section{El model i la xarxa}

El model bàsic de les comunitats del Projecte Shere Rom ha estat desenvolupat per una xarxa d'equips d'universitats d'Estats Units, América Llatina i Europa, entre les que es troba la UAB, sota el nom comú de Cinquena Dimensió (Cole, 2006; Nilsson \& Nocon, 2005). La Cinquena Dimensió (5D) pretén construir un context d'activitat on la utilització creativa de les noves tecnologies permeti desenvolupar les competències necessàries per la inclusió escolar dels participants, i a on es posin a l'abast de la població jove noves formes d'utilització de les TIC. El seu desenvolupament es dona dins i fora de l'escola, però en tots els casos s'orienta a la creació d'un entorn on els participants comparteixen significats, metes i eines. Aquest entorn es pot considerar una microcultura en construcció permanent a partir de les aportacions dels participants. Descrita en poques paraules, consisteix en la col-laboració d'un grup de nois i noies d'ensenyament primari o secundari amb un grup d'estudiants universitaris en la resolució de tasques mitjançant la utilització de software divers, i traçant un recorregut d'activitats o missions que segueixen unes regles.

Els projectes inspirats en el model 5D es fonamenten en el marc conceptual de la Psicologia Cultural (Cole, 1999; Rogoff, 1993). Des d'aquesta perspectiva, la construcció del coneixement és un procés social basat en la participació i la col·laboració entre actors que posseeixen coneixements i experiències distintes. La seva trobada, sota determinades condicions, es produeix en la Zona de Desenvolupament Pròxim, en la qual l'aprenent, mitjançant la guia de l'expert, adquireix progressivament l'autonomia en noves tasques. 
Els rols d'expert i aprenent són flexibles, i un mateix subjecte pot transitar entre l'un i l'altre segons els objectius i les activitats concretes. També s'inspira en la pràctica de la Psicologia Comunitària, entenent que l'activitat educativa ha d'estar vinculada a la comunitat on es porta a terme, amb la finalitat que l'aprenentatge sigui significatiu i es connecti als objectius comunitaris. Els nens i les seves famílies deuen ser respectats i considerats com interlocutors amb capacitat per a formular i perseguir uns objectius i, per tant, per transformar l'activitat.

Finalment, la 5D suposa sempre la participació d'estudiants universitaris en col-laboració amb els nois i noies de les comunitats o escoles en què es desenvolupa el projecte a la manera de companys amb experiència en l'àmbit formal. No es tracta tan sols d'un recurs (voluntariat), o unes pràctiques sinó d'una modalitat d'Aprenentatge Servei (ApS) universitari, en tant que la participació de l'alumnat universitari en el projecte suposa aprenentatge, servei a la comunitat i reflexió. L'aprenentatge deriva de la participació en el projecte i s'articula en el marc d'assignatures sobre desenvolupament infantil, disseny educatiu, intervenció comunitària o psicologia cultural. Proporcionen un servei real a la comunitat, en tant que són agents de la intervenció i subjectes necessaris pel seu desenvolupament, ja que aquesta es basa en la seva col-laboració en qualitat d' «experts». Finalment hi ha pautat un marc de reflexió (imprescindible en ApS) individual a través de diaris de camp i col-lectiu a través de posades en comú i processos de decisió amb els professionals (mestres i investigadors) que participen en el projecte.

Els espais del Projecte Shere Rom (s'han arribat a desenvolupar en 17 indrets diferents de l'Àrea Metropolitana de Barcelona al llarg de 21 anys, vuit escoles, tres instituts, un institut-escola, tres associacions gitanes, un centre cívic i una biblioteca) funcionen autònomament, i es desenvolupen de manera que presenten grans diferències entre sí, sempre cercant l'adaptació als respectius contexts, però s'articulen com una xarxa (Crespo, Lalueza, Lamas, Padrós i Sánchez-Busqués, 2014; Padrós, Sánchez-Busqués, Lalueza i Crespo, 2014).

En aquest article analitzarem l'espai del Projecte Shere Rom desenvolupat al barri de Bon Pastor en una escola pública d'educació infantil i primària amb una població formada per aproximadament la meitat dels alumnes d'ètnia gitana i l'altra provinent de la immigració de països d'Àfrica (majoritàriament Marroc), Àsia (Pakistan i també Xina) i Amèrica Llatina. Es tracta d'una escola que ha patit fenòmens de segregació en tant que la població autòctona no gitana ha evitat durant anys matricular als seus fills en ella al percebrela com un gueto i amb presència d'alguns alumnes pertanyents a famílies conegudes en el barri com conflictives. Tot i això des de les entitats gitanes que treballen en el barri s'ha manifestat que aquesta escola ha fet un gran esforç en la comunicació amb les famílies i en la inclusió educativa dels membres de la seva comunitat. A pesar que l'absentisme i abandonament escolar al llarg de la primària ha estat anecdòtic en aquesta escola, el centre públic de secundària del mateix barri, al que acudia la major part dels seus alumnes, presentava uns nivells d'abandonament precoç o fracàs en l'obtenció del graduat en ESO superiors al 80\%. Així, des del cus 2017-18 s'ha integrat la secundària obligatòria en l'antic centre de primària, esdevenint així un institut-escola. Dos anys després, la matrícula de preescolar s'ha incrementat, obrint una segona línia de P3 i incloent alumnat autòcton no gitano per primera vegada en anys.

El projecte es va iniciar al març de 2006 amb el grup de 4rt de primària, continuant fins que els mateixos alumnes van acabar 6é. Durant els anys posteriors, 12 promocions 
de nois i noies han participat en el projecte entre dos i tres anys. Durant aquest temps, l'activitat ha estat apropiada com un projecte de centre, amb la progressiva implicació de la direcció i un nombre creixent de mestres, en col·laboració amb els investigadors i estudiants de la UAB.

\section{Com funciona l'activitat?}

Quan un infant comença per primera vegada l'activitat, un estudiant li ajuda a fer una carta per a @Mac, un personatge misteriós que ningú no ha vist, però que respon les cartes, participa en xats i envia missatges a fòrums compartits pel grup. Aquesta ambigua i misteriosa figura es relaciona i es comunica de diferents maneres amb els nens i nenes que participen en aquesta comunitat de pràctiques. La identitat del Mag és desconeguda i sovint es construeix com una entitat amb més d'un gènere i una personalitat que canvia contínuament. S'utilitza per a estimular la imaginació i el raonament dels nois. A més, sovint s'usa per a intervenir en conflictes i conduir l'atenció cap a altres contextos. En cada sessió, el primer pas es revisar si hi ha nous missatges d'@Mac. Una vegada completada cada tasca o joc, els nois li envien una carta. En funció de les competències assolides pels membres del grup, l'activitat es desenvolupa d'acord a tres models: Laberint, Trobadors i Ràdio Juvenil.

El Laberint és una activitat concebuda per introduir als nois i noies en l'ús de les TIC a través de la col-laboració amb companys experts, estudiants universitaris que treballen amb un o dos infants en la resolució de tasques (missions en les que s'han d'utilitzar eines TIC). Una modalitat de Laberint consisteix en l'Apadrinament, en el que els experts són nois i noies de més de 10 anys que ajuden a nens i nenes més petits.

Per participar es parteix de la representació gràfica d'un laberint que connecta diverses habitacions, i en cada una d'elles hi ha una o vàries propostes d'activitat que els nens i els seus acompanyants hauran de portar a terme. Cada activitat té una guia de tasques que explica què s'ha de fer un cop iniciat el joc. Hi ha tres nivells: principiant, iniciat i expert. Quan s'arriben a complir els requisits d'un dels dos últims nivells, es pot avançar a la següent casella del laberint i iniciar un nou joc. El «viatge» que el nen fa al llarg dels dies a través del laberint, es registra en un passaport personal. L'estudiant universitari és el company que pot ajudar a resoldre la tasca, donar pistes, fer de suport, proporcionar el llenguatge adequat... Al final, aquest estudiant fa un diari de camp on es detallen els progressos i les dificultats. De manera periòdica, @Mac manté contactes i respon a les cartes.

La lectura i l'escriptura són eines fonamentals que s'utilitzen sempre amb una meta explícita. Es llegeix per a informar-se d'alguna cosa relacionada amb l'activitat, s'escriu sempre per a una audiència, sigui un company, un personatge virtual, els potencials lectors d'un blog o els espectadors de les seves creacions. Lectura i escriptura tenen així una funció netament comunicativa i formen part d'un entrellaçat de requeriments i respostes on el component afectiu ocupa un lloc central. Aquest extracte del diari de camp d'una de les estudiants de la UAB que van participar il-lustra l'aproximació a les dificultats que nois i noies poden presentar per apropiar-se de l'escriptura com a eina:

...Cuando nos dimos cuenta, ya eran las 16.30, y debían marcharse. Concretamos rápidamente lo que teníamos que llevar al día siguiente, y les pedí que, mientras yo recogía, me apuntaran por favor en un papel lo que debía llevar el siguiente día, para que no se me olvidara. A. cogió el boli y lo escribió rápi- 
damente, y I. dijo que él escribía muy mal. Le dije que no pasaba nada, que lo escribiera que lo importante era que yo no me olvidara de llevar las cosas. Le di un poco de prisa para que se olvidara de si escribía bien o mal y me lo escribiera, «haciéndome el favor de escribirlo», y entonces lo escribió. Me gustó porque, aunque no quería, escribió igualmente y aunque le costó, lo hizo. Yo le dije que muchas gracias que así ya no se me olvidaría. No miré su letra y guardé el papel directamente porque no quería que pensara que yo me fijaba en eso. Había conseguido que escribiera y pensé que lo importante es que, siendo que él tiene esa percepción sobre su propia escritura, no se sintiera juzgado, ni incómodo. Entonces, acabamos de guardar todo, nos despedimos, y se fueron.

Amb el temps, les TIC s'han anat introduint a l'escola, i el professorat s'ha apropiat d'estratègies com la del laberint per treballar-les de manera significativa durant els primers cursos de primària. Això ens ha alliberat d'aquest primer pas d'aprenentatge de les $\mathrm{TIC}$ i ens hem centrat en desenvolupar activitats orientades a construir narratives. Així, amb els alumnes de 5é i 6è de primària hem dut a terme la construcció de narracions digitals mitjançant la dinàmica Trobadors, i amb els de 1er i 20 d'ESO hem experimentat amb una Ràdio Juvenil digital.

Trobadors és un model orientat a la creació de petits relats digitals per tal de donar als nens l'oportunitat de ser creadors i participants actius en el seu procés d'aprenentatge. S'organitza en grups de tres o quatre nens i nenes acompanyats per un o una estudiant $i$ entre tots ells elaboren presentacions dinàmiques, animacions o pel.lícules de vídeo de curta durada sobre un tema escollit pel propi grup. El procés d'elaboració del relat es realitza de forma colllaborativa i amb l'ajut d'eines com càmeres i programes d'edició de vídeo. El procés de realització passa per diferents fases: planificació del treball a realitzar, selecció de la temàtica, elaboració del guió, gravacions, edició i, finalment, visualització. Però aquest procés no és lineal sinó que opera en espiral. És a dir, cada visualització porta a la revisió del que s'ha fet, de manera que no hi ha una avaluació externa, sinó una reflexió permanent dels autors sobre la seva obra. Llibertat per escollir, activitat cooperativa i treball orientat a una audiència són els tres eixos fonamentals d'aquesta activitat.

\footnotetext{
...Seguidamente, pregunté qué escenas querían grabar hoy y A. rápidamente señaló la tercera escena, en la que él sale. I. dijo que él grabaría y N. dijo que, además, debíamos repetir la primera escena ya que habíamos hecho algunos cambios y si la repetíamos podría quedar mejor. Les propuse que, si les parecía bien, las grabáramos en orden, por lo que empezaríamos por la de N.. Les gustó la idea, así que nos pusimos manos a la obra. N. me preguntó si había traído la chaqueta y le dije que sí. Saqué de la bolsa la gabardina para que N. hiciera de detective, y el móvil. Me dijo: iqué guay! y se puso muy contento porque le hacía ilusión ponérsela. Entonces, A. se ofreció para grabar y, aunque I. le dijo que lo había dicho él primero, manifestó que no le importaba, que él podría grabar la siguiente. Estuvimos unos minutos barajando diferentes sitios desde los cuales grabar. Finalmente, decidimos grabar desde una de las mesas. Pusimos la alarma del móvil, para que sonara y para que Nino hiciera cómo si cogiera el teléfono. Entonces, grabamos la escena por primera vez.
}

És fonamental la implicació dels participants en un procés complex, ja que s'ha de compartir una meta final a la que s'arriba a través de tasques subordinades. El compromís dels nois i noies sorgeix de la colllaboració amb l'estudiant, que ha de vetllar per treballar en la «zona de desenvolupament pròxim», cedint la iniciativa a aquells sempre que sigui possible, i construint una estructura d'ajuda, una mena de «bastida» que es va retirant a mida que «l'edifici» es construeix i va guanyant solidesa.

\footnotetext{
...Me dijo que mejor escribiera yo, así que me puse a escribir, pero lo hice con una letra mal hecha. Le dije que si la entendía y dijo que más o menos, así que volví a sugerirle que sería mejor que lo escribiera él. N. cogió el boli y escribió el guión. Me puse muy contenta porque escribió muy bien. Volvimos a grabar la escena, pero no quedó bien porque N. se puso un poco nervioso y se encalló, por lo que la volvimos a repetir. En esta ocasión salió bien, pero A. le propusieron repetirla otra vez por si acaso. Me pareció muy bien y me gustó que quisieran asegurarse que quedaba bien, porque esto me demuestra que están muy implicados con la película y lo sienten un proyecto muy «suyo». Repetimos la escena, y nos pusimos a trabajar sobre la segunda, en la que A. contestaba a la conversación telefónica de N.
} 
Intentamos grabarlo en el pasillo, pero vimos que había demasiado ruido, por lo que entramos de nuevo en la clase y grabamos en otro rincón de la clase. l. grabó la escena, la cual repetimos 3 veces hasta que salió bien.

La creació de vídeos digitals suposa la construcció d'un producte final dirigit a una audiència. D'aquesta manera es compromet la pròpia identitat en la tasca a desenvolupar, ja que es presenta a persones significatives pels nois i noies (companys, família, mestres, membres de la comunitat...).

Finalment, amb l'inici dels cursos de secundària al convertir-se el centre en un Institut-Escola, hem desenvolupat un tercer model d'activitat, un canal de Ràdio Juvenil que s'orienta a establir un diàleg entre l'escola i la comunitat. Per als nois i noies és una nova etapa i el moment ideal per dir adéu a @Mac, figura imaginària que els ha acompanyat durant la primària. Ja no tenen per tant la tutela d'aquest ens, i radica en ells i elles la responsabilitat de prendre les decisions que duen el projecte a bon port. Per tal d'implicar-los hem seguit una metodologia pròpia dels «Fons d'Identitat» (Esteban-Guitart, Llopart i Subero, 2016) que suposa indagar, a través dels seus interessos i de les seves emocions, els temes que poden resultar motivadors.

\begin{abstract}
...saco sucesivamente los objetos, algunos se nota que improvisaron y pusieron cualquier cosa para cumplir con la tarea, pero a la hora de hablar argumentaron bien porque se dieron cuenta que la actividad los demás sí la tomaron en serio, Z. Ilevó una muñeca que le había regalado su abuela y tenía desde pequeña, B. un peluche que era importante porque lo tenía desde los 5 años, nos contó que cuando él creció un día fueron con su padre y ambos se compraron la misma camiseta que llevaba puesto el osito. Sigue la ronda y los chicos van contando la historia de su objeto y por qué es importante para ellos. Llega el turno de M., quien indica "yo he traído mi nombre», yo le digo que está muy bien, le pido que explique qué significa para él, me dice es que en mi religión es muy importante.
\end{abstract}

Un cop acordat el centre d'interès que pot compartir un grupet de tres o quatre nois i noies, es defineix un «programa» de ràdio al voltant d'aquest tema, el que suposa documentar-se, realitzar «vox pop» o entrevistes al carrer, entrevistes en profunditat en un estudi, cerca de sintonies, realització d'espots, etc. La meta és connectar els interessos dels participants amb les necessitats de la comunitat, i esdevenir així un servei de la mateixa, difuminant les barreres entre el centre educatiu i el seu entorn.

\title{
Anàlisi de la sostenibilitat del projecte
}

El projecte Shere Rom es pot conceptualitzar com una recerca per disseny (experiment per disseny per Cole, 2016, o experiment de disseny social per Gutiérrez i Vossoughi, 2010). Inicialment concebuts com laboratoris naturals per estudiar processos educatius que involucren estudiants minoritaris en els seus contextos comunitaris, els espais Shere Rom aviat van evolucionar fins a convertir-se en intervencions educatives destinades a assolir objectius de la comunitat o de l'escola, així com l'aprenentatge dels estudiants de grau. D'aquesta manera, els diferents espais, més enllà dels originals objectius de recerca, van acollir una multiplicitat de socis amb diferents motius, que a través de les seves contradiccions i complementarietats van contribuir a l'evolució de cada espai Shere Rom.

L'espai de Bon Pastor és un d'aquests experiments per dissenyi ha evolucionat al llarg de catorze anys gràcies als processos de negociació que partien d'aquesta convergència de motius diferents i de vegades contradictoris entre investigadors, mestres, equip directiu de l'escola, estudiants universitaris i estudiants de l'escola. Per tal d'analitzar els factors de sostenibilitat d'aquest tipus de projectes de collaboració, atendrem a dos principis 
proposats per Engeström (2001) en l'estudi dels sistemes d'activitat: la historicitat i la multivoceïdat.

Pel que fa a la historicitat, sempre que els sistemes d'activitat prenen forma i es transformin en llargs períodes de temps, els seus problemes i potencials només es poden entendre en la seva pròpia història «com l'estudi de la història local de l'activitat i els seus objectes, i com a història de les idees i eines teòriques que han configurat l'activitat» (Engeström, 2001, p. 136). L'evolució de l'espai de Bon Pastor no és independent de la història del context social i del centre educatiu, que es percep com un centre segregat, amb població immigrant i població gitana com la única «autòctona». L'acollida d'un projecte de recerca es fa des de la premissa de la seva utilitat immediata per a la inclusió educativa i la lluita contra el fracàs escolar. En un principi, I'alfabetització ordinària i l'alfabetització digital són metes essencials en el treball educatiu amb una població que presentava fortes carències socioeconòmiques i un elevat risc d'abandonament escolar tot just en acabar els estudis primaris. La «fidelització» de l'alumnat i les seves famílies van evitar un abandonament més precoç, i està en l'origen de la seva conversió en institut-escola.

Així, el projecte Shere Rom ha hagut d'adaptar-se a les demandes sorgides d'aquesta situació. La seva sostenibilitat depèn de la seva eficàcia per ser una experiència significativa pels nois i noies que hi participen. D'altra banda, en tant que suposa una clara distorsió dels ritmes i formes de procedir habituals en l'aula, només pot continuar curs rere curs si la seva marxa es valorada positivament pel professorat i compta amb l'adhesió dels alumnes (Lalueza, Sánchez-Busqués i García-Romero, 2020).

Però és en la multivoïceitat, és a dir, la concurrència d'una multiplicitat de veus (Bakhtin, 1986) expressant els motius de diferents tipus d'actors, on radica el principal repte per la sostenibilitat del projecte. Un sistema d'activitat és sempre una comunitat de múltiples punts de vista, tradicions i interessos. La divisió del treball en una activitat crea diferents posicions per als participants que porten les seves pròpies històries diverses, i el propi sistema d'activitat porta múltiples capes i fils d'història gravats en els seus artefactes, regles i convencions (Engeström (2001). Tanmateix, la multivoceïdat en l'espai de Bon Pastor s'explica millor pel fet que els seus participants formen una part simultània dels altres sistemes d'activitat implicats. Investigadors i estudiants universitaris intervenen no només com a participants a l'activitat a l'escola, sinó també com a membres de la universitat com a sistema d'activitat. Els mestres formen part del sistema escolar però juguen un rol molt diferent en l'activitat 5D. Aquesta no és només una transició entre sistemes, sinó també un sistema híbrid; és un tercer espai en el llenguatge de Gutiérrez, BaquedanoLópez i Tejeda (1999), dirigit a un tercer objecte (Engeström, 2001) o a un objecte dual (McMillan, Goodman i Schmid, 2016), ja que prové de la fusió o la hibridació dels objectes dels sistemes d'activitat originals. És el resultat de diferents processos històrics, diferents sistemes de construcció, significats o tradicions.

Podem aclarir el paper de la multivoceïdat atenent els motius que impulsen l'acció dels participants. Per entendre la dinàmica dels processos psicològics, hem de destacar el caràcter final de l'activitat humana, que es determina i s'estructura mitjançant l'anticipació dels efectes perseguits. En el marc explicatiu descrit per Leontiev (1978), les activitats expressen els motius dels participants. Aquestes activitats es materialitzen al nivell d'accions, que es fan intel-ligibles amb els objectius que les guien; un objectiu és la representació del resultat esperat de la realització concreta de l'acció. En tots els contextos d'activitat, la multiplicitat de veus expressa diversos motius i, per tant, una diversitat 
d'objectius que conflueixen en les mateixes accions concertades. Al mateix temps, aquestes accions conjuntes poden conduir a objectius comuns mitjançant la creació d'un sentit compartit. Leontiev va proposar el concepte de sentit com a mecanisme regulador entre l'acció i l'activitat. El sentit és el grau d'articulació entre el motiu de l'activitat i l'objectiu d'una acció que materialitza aquesta activitat (Sebastián, Gallardo i Calderón, 2016). Així, el repte és crear un sentit compartit entre tots els participants identificant objectius comuns. El sentit compartit es consolida a mesura que transcendeix «l'activitat fronterera», en què els participants es veuen impulsats per diferents motius, que en principi responen a objectius dels sistemes d'activitat originals que generen una ideocultura en què el sentit de l'activitat és compartit (intersubjectivitat) i s'estableixen objectius compartits (Cole, 1996).

Però què implica la concurrència de múltiples veus? Com s'aconsegueix la creació d'aquesta ideocultura en el projecte que hem descrit? Considerem que hi ha quatre factors principals, el seu caràcter col/laboratiu, la seva apropiabilitat, la seva estructura narrativa i la promoció de l'agentivitat

Les comunitats de pràctiques són la principal via d'accés als significats socials, i aquestes comunitats es caracteritzen pel treball col/laboratiu (Rogoff, Matusov i White, 1996; Wenger, 2001). Aquesta filosofia es manifesta en l'estructura de l'activitat, on es poden prendre diferents camins en funció de les motivacions, i en les relacions entre aprenents i experts (o entre diferents aprenents), que han de posar-se d'acord sobre com portar a terme la tasca. El treball col-laboratiu permet la construcció d'una ideocultura en la qual adults i infants col-laboren en la creació d'un projecte compartit. Aquesta ideocultura genera un espai interinstitucional (universitat, escola, entitats socials), intergeneracional (adults professionals, joves estudiants i infants) i intercultural (diverses cultures institucionals, generacionals i comunitàries) en el qual s'expressen veus diferents, i a on es dilueixen les relacions de poder relacionades amb l'edat, el gènere o la procedència cultural, generant dinàmiques de treball on les normes i els rols puguin ser negociats a cada moment. Finalment la figura d'un adult com a col/laborador, i no com avaluador del nen, facilita la creació de forts vincles afectius que promouen el procés d'aprenentatge, així com una major implicació de tots i totes en el propi procés d'aprenentatge.

L’adaptabilitat i apropiabilitat (Rogoff, 2003) del model significa una especial sensibilitat a les característiques i necessitats dels contextos institucionals en què es realitza. El Projecte Shere Rom és adaptable a les cultures locals, ja que no hi ha un currículum tancat i les activitats i continguts són definits pels propis participants. Així, si es duu a terme en una escola, el disseny concret atén a les característiques del grup, als interessos dels mestres i la dinàmica de l'escola; però també té en compte el context social, les característiques del barri i els marcs culturals comunitaris als que pertanyen les famílies dels alumnes. Suposa, per tant, l'explícita presa en consideració de les cultures que convergeixen a l'aula. I si es realitza en una associació gitana, el disseny ha d'atendre a les constants interaccions amb les persones i grups que participen en altres activitats, amb les famílies dels infants (incorporant per exemple als germans més petits), i als objectius de la mateixa associació. Les cultures locals i la cultura acadèmica majoritària poden acomodarse en contextos d'aprenentatge socialment productiu. Així, no s'imposen significats, sinó que es crea un espai on diferents interessos i motivacions poden trobar-se. Primer «a la frontera» on cada un té les seves pròpies metes, realitzables a través de l'acció conjunta: 
pels nens jugar, resoldre un misteri o manifestar les seves habilitats; pels mestres desenvolupar determinades competències dels alumnes; pels estudiants aprendre sobre desenvolupament i educació a través de la pràctica; pels membres actius de l'associació empoderar la seva comunitat a través de pràctiques que suposin l'adquisició de noves competències i coneixements. Però, a mesura que els diferents artefactes de l'activitat són apropiats per tots els participants, es va construint una ideocultura en la que emergeixen significats i metes compartides. Quan això succeeix, els participants s'han apropiat del model, ho han fet seu, i l'ulterior desenvolupament pot ser ja gestionat per ells mateixos.

La narrativitat és un element essencial per dotar de significació a l'activitat. L'experiència esdevé significativa quan pot ser narrada (Bruner, 1991, 1996). Donem sentit a les coses que ens passen construint un relat versemblant per nosaltres mateixos, ordenant els esdeveniments en unitats que d'alguna manera presenten un plantejament, un nus i un desenllaç. El pensament conceptual és un resultat de l'escolarització, però no pot ser un prerequisit per accedir a l'escola, mentre que el relat és una forma d'organització del sentit universal, present a totes les cultures, que pot ser utilitzar com via d'accés a la pràctica escolar. Una de les dificultats per integrar l'extensa oferta de software educatiu consisteix en la creació d'un fil conductor que el vinculi a l'activitat. A l'escola, l'ordinador apareix sovint com una eina que, quan s'acudeix a ella, trenca el ritme i el sentit de la dinàmica de la classe. En canvi, la incorporació d'una narrativa contribueix a integrar les eines en una activitat dirigida a metes (és a dir, amb sentit). En el model 5D, l'activitat es presenta als infants com un relat en què un o varis personatges tenen un passat, plantegen un conjunt d'accions significatives, mantenen una relació continuada en el temps amb els participants i contribueixen a crear una història comuna compartida per aquests en una sort de «complicitat». No es tracta, per tant, d'un conjunt d'activitats desconnectades entre sí, ni tampoc d'una estructura programada per a l'adquisició de conceptes. L'activitat és un tot narratiu, que es pot explicar amb el llenguatge dels participants perquè té un plantejament explícit, transcorre mitjançant regles conegudes i té un desenllaç que pot ser tant l'arribada al final d'un trajecte (laberint), com la presentació del producte creat collectivament (trobadors), o l'establiment d'un diàleg amb la comunitat (ràdio juvenil). En l'espai de Bon Pastor, @Mac juga un paper important en la creació d'aquest fil narratiu. És un personatge viu, que reconstrueix la història del grup perquè en guarda memòria, i fomenta projectes de futur en forma de reptes.

Per últim, el Projecte Shere Rom pretén promoure l'agentivitat, és a dir, afavorir en els participants la competència i la consciència de guiar la seva pròpia activitat d'aprenentatge, a través de l'autoria i la representació conscient de l'audiència. L'autoria, el discurs conscientment adreçat a una audiència, és un element fonamental en la construcció del significat, així com en l'entrada en els significats de la cultura (Bakhtin, 1986; Wertsch, 1991). Així, en les activitats que hem denominat Trobadors i Ràdio Juvenil, nois i noies prenen un paper que generalment no acostumen a gaudir: són ells els agents en tot el procés, la decisió del que volen explicar ha de ser seva, i la revisió de la qualitat o l'adequació de la obra és també seva. Són ells qui marquen el ritme, prenen les decisions, reflexionen, creen i actuen. Adopten un paper actiu en el diàleg amb l'espectador i narren la seva història des d'una posició privilegiada, amb veu pròpia. S'ofereix així, des de bon començament, la possibilitat de veure's des d'una altra perspectiva, com autors i participants de tot allò que estan realitzant. 


\section{Conclusions}

Les propostes d'activitat del Projecte Shere Rom trenquen amb la dinàmica pròpia de l'escola tradicional. En front d'un procés de transmissió de la informació lineal, de dalt a baix, es proposa una dinàmica de col-laboració, descoberta i creació horitzontal amb una multiplicitat d'actors (alumnes, estudiants universitaris, mestres, investigadors, agents comunitaris...). Un procés així precisa de la negociació constant i l'establiment explícit de metes compartides. Però aquest és un procés difícil perquè tots els interlocutors participants parteixen de motivacions diferents. En les institucions d'educació formal, la pressió del currículum, de les formes institucionalitzades de funcionament de l'escola, condueixen a una pèrdua de flexibilitat del model. La urgència d'aconseguir uns nivells de coneixements i competències i, sobretot, el manteniment d'unes normes de funcionament amb una població a la que costa molt acceptar-les i complir-les, poden fer perdre de vista un procés necessàriament lent, i en el que la prioritat no pot deixar de ser que l'activitat sigui significativa.

Investigadors, mestres, estudiants universitaris i alumnes de l'institut-escola, participen en sistemes amb regles, formes de funcionament $\mathrm{i}$ jerarquies que li són pròpies. El repte esdevé crear espais compartits, és a dir, ideocultures que donin significat a les activitats que es duen a terme. El repte és ser capaços de crear un espai d'interrelació on l'activitat tingui sentit per tots els interlocutors (encara que aquest sentit sigui diferent per uns i altres). Això implica un reconeixement de l'altre com quelcom legítim, com a participant actiu del procés.

Al crear espais de relació interinstitucional, I'activitat ha de tenir sentit per a cada entitat, el que vol dir recollir els objectius legítims de cadascuna, l'escola, la universitat. En tant que espais intergeneracionals, ha de ser significativa pels diferents participants, alumnes de l'escola, estudiants universitaris, mestres, investigadors i professors universitaris. I en tant que espai intercultural, ha de generar narratives que siguin formulables en diferents llenguatges socials, han de tenir sentit per les diferents comunitats implicades. Això només és possible amb una constant negociació. El projecte va sorgir d'una negociació intercultural (Crespo, Lalueza i Pallí, 2002) i el seu futur radica en una negociació més complexa i duradora.

\section{Referències}

Bakhtin, M.M. (1986) Speech Genres and Other Late Essays. Austin, University of Texas Press.

Bruner, J.S. (1991) Actos de Significado: más allá de la revolución cognitiva. Madrid, Alianza. Bruner, J.S. (1996) La educación, puerta de la cultura. Madrid, Visor.

Cole, M. (1999) Psicología Cultural. Madrid, Morata.

Cole, M. (2006) The Fifth Dimension: an after-school program built on diversity. New York, Russell Sage Foundation.

Cole, M. (2016) «Designing for development: Across the scales of time». Developmental Psychology, 52 (11), p. 1679-1689.

Cole, M. i Derry, J. (2005) «We Have met Technology and It Is Us» a Sternberg, R.J. i Preiss, D. [Eds.] Intelligence and Technology: The Impact of Tools on the Nature and Development of Human Abilities. Hillsdale NJ, Lawrence Erlbaum Associates, p. 209227.

Crespo, I.; Lalueza, J.L. i Pallí, C. (2002) «Moving communities: a process of negotiation with a gypsy minority for empowerment». Community, Work and Family, 5 (1), p. 4966.

Crespo, I.; Lalueza, J.L.; Lamas, M.; Padrós, M. i Sánchez-Busqués, S. (2014) «El proyecto Shere Rom. Fundamentos de una comunidad de prácticas para la inclusión educativa 
de grupos culturales minoritarios y en riesgo de exclusión social». Psicología, Conocimiento y Sociedad 4 (2), p. 138-162.

Engeström, Y. (1999) «Innovative learning in work teams: Analyzing cycles of knowledge creation in practice» a Engeström, Y.; Miettinen, Y. i Punamäki, R.L. [Eds.] Perspectives on Activity Theory. Cambridge, Cambridge University Press, p. 377-404.

Engeström, Y. (2001) «Expansive learning at work: Toward an activity theoretical reconceptualization». Journal of Education and Work, 14 (1), p. 133-156.

Esteban-Guitart, M.; Llopart, M. i Subero, D. (2016) «La aproximación de los fondos de conocimiento e identidad. La conexión del currículum y la práctica escolar con los contextos y formas de vida de los aprendices». Papeles de Trabajo sobre Cultura, Educación y Desarrollo Humano, 12 (3), p. 13-19.

Fernández-Enguita, M. (1994) Escuela y etnicidad: el caso del pueblo gitano. Madrid, CIDE.

Gutiérrez, K. D., Baquedano-López, P. i Tejeda, C. (1999) «Rethinking diversity: Hybridity and hybrid language practices in the third space». Mind, Culture, and Activity, 6 (4), p. 286-303.

Gutiérrez, K.D. i Vossoughi, S. (2010) «Lifting off the ground to return anew: Mediated praxis, transformative learning and social design experiments». Journal of Teacher Education, 61 (1-2), p. 100-117.

Lalueza, J.L.; Crespo, I. i Camps, S. (2008) «Las tecnologías de la información y la comunicación en los procesos de desarrollo y socialización», a Coll, C. i Monereo, C. [Eds.] Psicología de la Educación Virtual. Madrid, Morata, p. 54-73.

Lalueza, J.L.; Sánchez-Busqués, S. i García-Romero, D. (2020) «Following the trail of the 5th Dimension: University-community partnership to design educational environments». Mind, Culture \& Activity, 27 (2), p. 132-139. https://doi.org/10.1080/ 10749039.2019.1611859

Leontiev, A.N. (1978) Activity, consciousness, and personality. Englewood Cliffs NJ, Prentice-Hall.

McMillan, J.; Goodman, S. i Schmid, B. (2016) «llluminating "Transaction Spaces" in Higher Education: University-Community Partnerships an Brokering as "Boundary Work"». Journal of Higher Education Outreach and Engagement, 20(3), p. 8-31.

Nilsson, M. i Nocon, H. (2005) School of Tomorrow. Teaching and Technology in Local and Global Communities. Berna, Peter Lang.

Ogbu, J.U. (1994) «From Cultural Differences to Differences in Cultural frame of Reference», a Greenfield, P.M. i Cocking, C. [Eds.] Cross-cultural Roots of Minority Child Development. Hillsdale, LEA, p. 365-391.

Padrós, M.; Sánchez-Busqués, S.; Lalueza, J.L. i Crespo, I. (2014) «The Shere Rom Project: Looking for Alternatives to the Educational Exclusion of Roma». International Journal for Research on Extended Education, 2 (2), p. 46-62.

Rogoff, B. (1993) Aprendices del pensamiento. El desarrollo cognitivo en el contexto social. Barcelona, Paidós.

Rogoff, B. (2003) The Cultural Nature of Human Development. Oxford NY, Oxford University Press.

Rogoff, B.; Matusov, E. i White, C. (1996) «Models of teaching and learning: participation in a community of learners", a Olson, D. i Torrance, N. [Eds.] The handbook of education and human development. Cambridge MA, Blackwell, p. 388-414

Sebastián, C.; Gallardo, G. i Calderón, M. (2016) «Sentido identitario de la formación. Una propuesta para articular el desarrollo de la identidad y el aprendizaje en contextos educativos». Papeles de Trabajo sobre Cultura, Educación y Desarrollo Humano, 12 (3), p. 4-12.

Wenger, E. (2001) Comunidades de práctica. Aprendizaje, significado e identidad. Barcelona, Paidós.

Wertsch, J. (1991) Voices of the mind. London, Harvester Wheatsheaf. 


\section{Comunidades de prácticas para la inclusión educativa. Una «investigación basada en el diseño»}

Resumen: El Proyecto Shere Rom es una investigación basada en el diseño iniciada hace veintiún años. En este artículo se describe uno de los espacios de este proyecto desarrollado durante catorce años en una escuela del barrio barcelonés del Bon Pastor, con población con alto riesgo de exclusión social. Esta experiencia está basada en el modelo "Quinta Dimensión», orientado al desarrollo de comunidades educativas interinstitucionales, intergeneracionales e interculturales que promueven prácticas de aprendizaje colaborativo apoyado en el uso de las tecnologías de la información y la comunicación. Se trata de espacios en los que chicos y chicas de la comunidad resuelven tareas o crean relatos digitales en cooperación con estudiantes universitarios involucrados en un programa de Aprendizaje Servicio (ApS). Se analiza la experiencia a partir de dos elementos propios del enfoque histórico-cultural de la Psicología, la historicidad y la multivoceidad (multiplicidad de voces), y de los retos derivados de su carácter colaborativo, la apropiabilidad por actores con diferentes motivos, la estructura narrativa y el fomento de la agencia a través de la autoría.

Palabras clave: Comunidades de prácticas, aprendizaje colaborativo, investigación por diseño, educación intercultural, aprendizaje servicio

\section{Les communautés de pratiques pour l'inclusion éducative. Une «recherche fondée sur la conception»}

Résumé: Le projet Shere Rom est une « recherche fondée sur la conception » qui a été lancée il y a vingt-etun ans. Cet article décrit l'un des espaces de ce projet développé pendant quatorze ans dans une école du quartier barcelonais de Bon Pastor, avec une population à haut risque d'exclusion sociale. Cette expérience s'appuie sur le modèle "Cinquième dimension », orienté vers le développement de communautés éducatives interinstitutionnelles, intergénérationnelles et interculturelles pour la promotion de pratiques d'apprentissage collaboratif fondé sur l'usage des technologies de l'information et de la communication. II s'agit d'espaces dans lesquels garçons et filles de la communauté accomplissent des tâches ou créent des récits numériques en coopération avec des étudiants universitaires impliqués dans un programme d'apprentissage-service (ApS). L'expérience est analysée à partir de deux éléments propres à l'approche historique et culturelle de la psychologie, à savoir l'historicité et la multiplicité de voix, et des défis dérivés de son caractère collaboratif, de l'appropriabilité pour des acteurs ayant différents motifs, de la structure narrative et de l'encouragement de l'agence à travers la paternité.

Mots clés: Communautés de pratiques, apprentissage collaboratif, recherche par conception, éducation interculturelle, apprentissage-service

\section{Communities of practice for educational inclusion. A «design-based re- search project»}

Abstract: The Shere Rom Project is a design-based study initiated 21 years ago. This article describes one of the spaces of this project carried out during 14 years in a school in the Barcelona neighbourhood of Bon Pastor, with a population at high risk of social exclusion. This experience is based on the «Fifth Dimension» model, aimed at developing inter-institutional, intergenerational and intercultural educational communities that promote collaborative learning practices supported by the use of information and communication technologies. These are spaces in which children from the community solve tasks or create digital stories in cooperation with university students involved in a Service Learning program. The experience is analysed based on two elements of the cultural-historical approach of psychology, historicity and multi-voices, and also in terms of the challenges derived from the collaborative nature of the project, the appropriation by actors with different motives, the narrative structure and the promotion of agency through authorship.

Keywords: Communities of practice, collaborative learning, design-based research, intercultural education, service learning 